\title{
Transarterial Treatment of Cranial Dural Arteriovenous Fistulas: The Role of Transarterial and Transvenous Balloon-Assisted Embolization
}

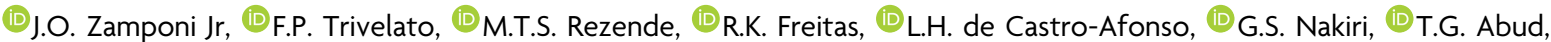

(1) A.C. Ulhôa, and DD.G. Abud

\begin{abstract}
BACKGROUND AND PURPOSE: Treatment of dural arteriovenous fistulas can be performed by transarterial or transvenous accesses. For those fistulas located at a dural sinus wall, obliteration of the sinus might lead to a substantial risk of complications if the occluded sinus impairs normal venous drainage. For those fistulas with direct leptomeningeal venous drainage, navigation to reach the arteriovenous shunting point of a leptomeningeal vein is usually technically demanding. We report the outcomes of patients with dural AVFs treated by transarterial injection of liquid embolic agents assisted by transarterial double-lumen balloon catheters and/or transvenous balloon catheters.
\end{abstract}

MATERIALS AND METHODS: This was a retrospective, 3-center study including patients with dural AVFs treated with a balloonassisted technique in at least 1 treatment session. Angiographic follow-up was performed at 6 months. Clinical assessment was performed at admission and discharge and was reassessed at 30-day and 6-month follow-ups.

RESULTS: Forty-one patients with 43 dural AVFs were treated. Thirty-four fistulas were located at a dural sinus wall. Treatment was performed using only a transarterial approach in 42 fistulas. Only 1 session was needed for complete obliteration of the fistula in $86 \%$ of the patients. Immediate complete angiographic occlusion was achieved in 39 fistulas. Of the 41 controlled fistulas, 40 (97.6\%) were completely occluded at 6 months. Thirty-nine fistulas (95.1\%) were cured without any report of major neurologic events or death during follow-up.

CONCLUSIONS: Transarterial balloon-assisted treatment of dural AVFs with or without transvenous balloon protection was shown to be safe and effective.

ABBREVIATIONS: DAVF = dural arteriovenous fistula; DLB = double-lumen balloon; DLVD = direct leptomeningeal venous drainage; MMA $=$ middle meningeal artery; NALEA = nonadhesive liquid embolic agent; OCC = occipital artery; TAA = transarterial approach; TVA $=$ transvenous approach; TVB $=$ transvenous balloon

ntracranial dural arteriovenous fistulas (DAVFs) are characterized by anomalous shunts located inside the dural leaves between the arterial and the venous systems. ${ }^{1-3}$ The venous drainage pattern of DAVFs determines their clinical presentation and prognosis and guides their therapeutic management. ${ }^{4}$

Treatment of a DAVF can be performed by transarterial (TAA) or transvenous (TVA) approaches. The TAA has been successfully used to treat DAVFs with direct leptomeningeal

Received May 20, 2020; accepted after revision July 7.

From the Division of Interventional Neuroradiology (J.O.Z., F.P.T., M.T.S.R., A.C.U.),

Felício Rocho Hospital, Belo Horizonte, Minas Gerais, Brazil; Division of

Interventional Neuroradiology (R.K.F., L.H.d.C.-A., G.S.N., D.G.A.), Hospital das

Clínicas, Medical School, University of São Paulo, Ribeirão Preto, São Paulo, Brazil;

and Division of Interventional Neuroradiology (T.G.A.), Hospital Israelita Albert

Einstein, São Paulo, Brazil.

Please address correspondence to Felipe Padovani Trivelato, MD, PhD, 3616

Timbiras St, Barro Preto, Belo Horizonte, Minas Gerais, Brazil 30320-670;

e-mail: felipepadovani@yahoo.com.br; @FelipeTrivelato

http://dx.doi.org/10.3174/ajnr.A6777 venous drainage (DLVD), while the TVA has been avoided in the treatment of this type of DAVF because navigation to reach the arteriovenous shunting point of a leptomeningeal vein is usually technically demanding and therefore riskier., ${ }^{2,3}$

For those DAVFs located within the dural sinus wall, transvenous embolization has been classically reported to provide a higher likelihood of cure than arterial embolization. However, complete obliteration of a dural sinus might lead to a substantial risk of complications if the occluded sinus impairs normal venous drainage. ${ }^{2,3,5}$

The major limitation for curative treatment of DAVFs with DLVD by the TAA is the extension of reflux of the liquid embolic agent along the arterial feeder before it reaches the venous side. ${ }^{6}$ Similarly, the use of a TVA to treat a DAVF of the dural sinus wall poses technical difficulties because there is limited control of the embolic agent penetration into the sinus, exposing it to inadvertent occlusion. ${ }^{1-3}$ 
To overcome these issues, preliminary case series have been published regarding the use of transarterial double-lumen balloons (DLBs) in association, or not, with transvenous balloons (TVBs) to treat DAVFs. ${ }^{6-13}$ This strategy allows the transarterial injection of embolic material without important reflux because its backflow is retained distal to the inflated balloon at the arterial feeder. The risk of inadvertent occlusion of the dural sinus by transarterial embolization has also been overcome because the possibility of TVB inflation inside the dural sinus ensures lumen protection. ${ }^{6-13}$ Additionally, the TVB can be inflated or deflated during treatment, according to the desired hemodynamic response intended to redirect the embolic agent toward the fistula.

The aim of this study was to report the clinical and angiographic outcomes of patients with DAVFs treated by transarterial injection of nonadhesive liquid embolic agents (NALEAs) assisted by a transarterial DLB catheter and or TVB.

\section{MATERIALS AND METHODS Study Design}

This was a retrospective, 3-center study that was conducted in accordance with the STrengthening the Reporting of OBservational studies in Epidemiology guidelines (https://strobe-statement.org/ index.php?id=strobe-home). It was approved by the ethics board of the institutions.

Inclusion criteria were as follows: 1) patients with intracranial DAVFs; 2) dural fistulas located at a sinus wall (Cognard type I or II) or with DLVD (Cognard type III, IV, or V); 3) a DAVF treated by TAA as a first-line therapy; and 4) use of a balloon-assisted technique in at least 1 treatment session.

The exclusion criteria were as follows: 1) a DAVF treated exclusively by TVA, without TAA; and 2) a DAVF for which balloon catheters were not used.

\section{Angiographic Analysis}

Occlusion of the DAVF after treatment was reassessed by conventional angiography at 6 months. Complete occlusion was defined as full obliteration of the fistulous zone, with no residual shunt or early venous drainage.

\section{Clinical Analysis}

Immediate and late serious clinical events were assessed during follow-up, including death and stroke. Other complications were also registered.

\section{Endovascular Procedure}

All 3 centers adopted the same treatment strategy. All interventions were performed with the patient under general anesthesia and systemic heparinization. Cerebral angiography was performed through femoral artery access. If a TVA was planned, venous access was obtained via the femoral vein. When intermittent angiographic control was needed aside from the cervical arterial treatment route (contralateral carotid artery or vertebral artery), contralateral femoral arterial access was obtained.

A $6 \mathrm{~F}$ guiding catheter was placed in the external carotid artery, giving branches to the DAVF. When a very challenging anatomy was faced, a triaxial system with a long sheath and guiding catheter with a malleable tip was combined.

The middle meningeal artery (MMA) was used as the primary treatment access route whenever possible because it presents with a commonly enlarged diameter when feeding a DAVF and due to its straight and embedded pathway in the dura. The occipital artery, which is considered a large-diameter vessel and consequently of difficult reflux control during NALEA injection, is even more dilated under hemodynamic stress when supplying a DAVF. Additionally, its tortuous transosseous branches toward the DAVF create higher resistance to NALEA progression. Thus, whenever one of these feeding arteries had a large enough diameter to permit balloon catheter navigation, catheterization was attempted (Fig 1).

A DLB catheter, $4 \times 11 \mathrm{~mm}$ (Scepter XC; MicroVention) was advanced over a 0.014-inch microguidewire (Transend 14 EX; Stryker) into the branch responsible for the DAVF supply, always trying to reach the fistulous zone or as close as possible to it. In rare cases, when the arterial feeder was very thin and tortuous, only the detachable tip microcatheter was used in association with a TVB.

For those DAVFs within the venous sinus wall, an $8 \times 80 \mathrm{~mm}$ remodeling balloon (Copernic RC; Balt Extrusion) was navigated over a 0.014 -inch microguidewire via the transvenous femoral route through a $6 \mathrm{~F}$ guiding catheter into the affected sinus covering the fistulous shunt. The balloon was temporarily kept inflated during transarterial injection of the embolic agent for a maximum of 7 minutes. To promote higher inflow of the embolic agent along the sinus wall, we performed transarterial injections intermittently as the balloon was deflated for a few seconds.

Transarterial embolization was performed after the DLB catheter was inflated, and its dead space was filled with dimethyl sulfoxide. Under continuous subtraction fluoroscopy, the NALEA (Onyx-18, Medtronic; or SQUID 18; Emboflu) injections were performed. When 2 arterial accesses were used, double injection was performed, simultaneously or alternately, depending on the penetration of the NALEA inside the fistulous zone (Fig 2).

A control angiography was performed to evaluate occlusion of the fistula, patency of the dural sinus if applicable, and complications.

\section{Data Collection}

All data were prospectively collected. Preoperative data included age, sex, clinical presentation, mRS score, DAVF location, Cognard type, feeding arteries, and draining veins or dural sinus involved. Operative data included the treated fistula, accessed vessels, use of balloons and/or microcatheters, embolic agent, and technical complications. Postoperative evaluation included the occlusion rate, complications, and mRS at discharge and at the 6-month follow-up.

Radiologic follow-up included 2 angiographies, immediately after the procedure and at the 6-month follow-up. Angiographic outcome was defined as complete occlusion or partial occlusion. Angiograms were evaluated by an independent neuroradiologist. Clinical outcomes were evaluated at 30-day and 6-month followups by independent neurologists, who examined and interrogated the patients about their own perception of symptom evolution, 


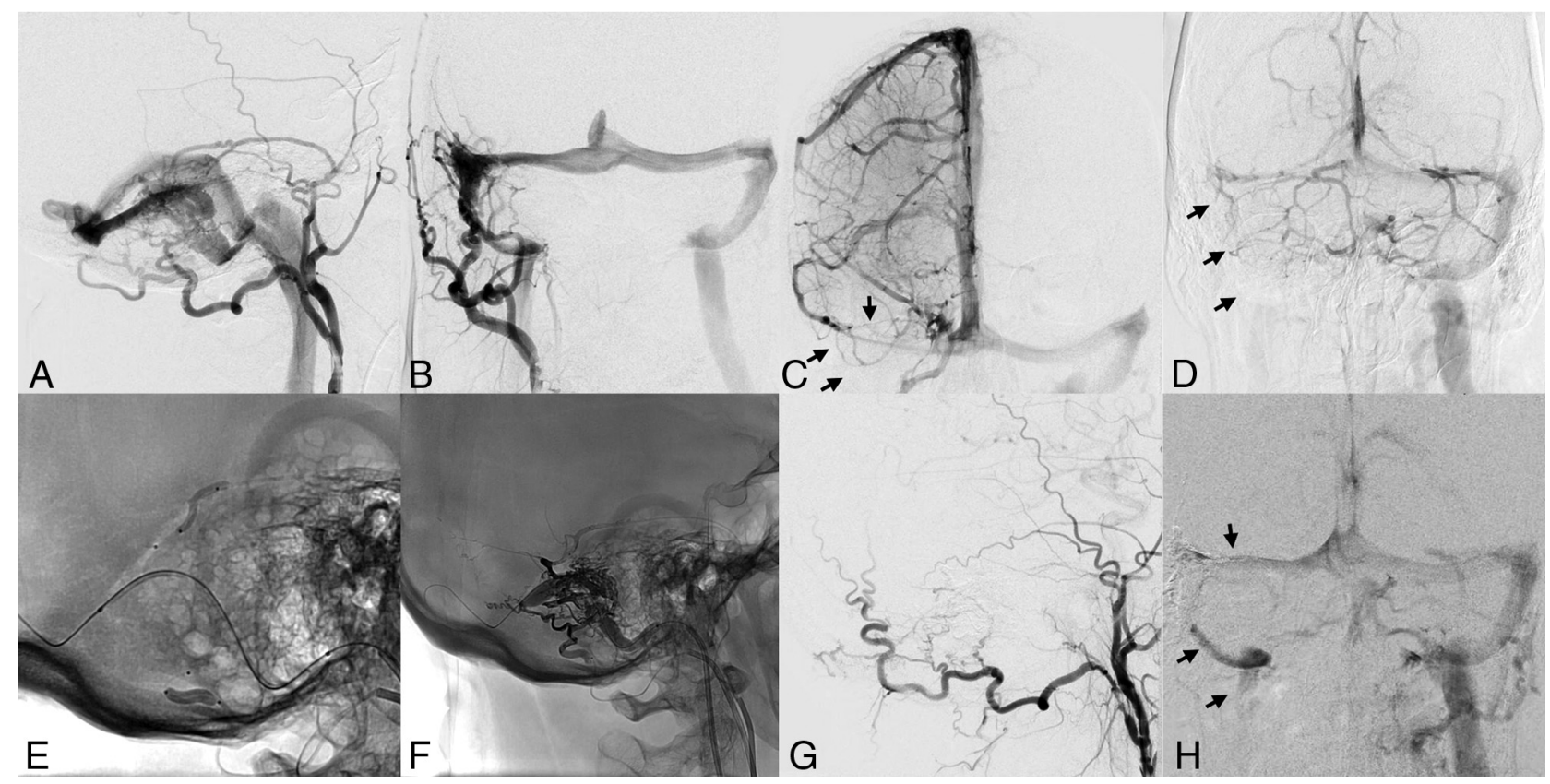

FIG 1. $A$ and $B$, Angiography shows a transverse-sigmoid sinus DAVF supplied by the OCC and MMA. $C$ and $D$, Venous phase of ICA and vertebral artery angiograms demonstrates that the right transverse and sigmoid sinuses are nonfunctioning (arrows). E, Note the position of the DLB catheters inside the petrosquamous branch of the MMA and inside the mastoid branch of the OCC. $F$, All 3 balloons are inflated, including the TVB. G, Control angiography reveals total occlusion of the DAVF. H, Venous phase of the ICA control angiogram demonstrates filling of the right transverse and sigmoid sinuses (arrows).

categorizing them as asymptomatic (complete resolution of previous symptoms) with clinical improvement or deterioration.

\section{RESULTS}

Between January 2016 and July 2019, forty-one patients with 43 DAVFs were treated in accordance with the inclusion criteria.

\section{Patient Demographics}

The mean age was $57.3 \pm 13.8$ years, and $53.7 \%$ were men. Four patients were asymptomatic, and 37, symptomatic (Table 1). Before treatment, 9 patients had an mRS score of zero, 21 patients had an $\mathrm{mRS}$ score of 1 , five patients had an mRS score of 2 , and 6 patients had an mRS score $>2$.

\section{DAVF Characteristics}

Twenty-one (48.8\%) fistulas were located at the transverse-sigmoid sinus; 8 (18.6\%), at the transverse sinus/torcula region; 7 $(16.7 \%)$, at the tentorial region; and 7 , in other locations.

Of the 34 DAVFs located at a dural sinus wall (79\%), the involved sinus was functional in 13 cases and nonfunctional in 21 $(61.8 \%)$ cases. Three fistulas presented with an isolated sinus (segment of the venous sinus discontinued from the other sinuses, mostly draining through leptomeningeal vein reflux). Nine DAVFs had DLVD. Most DAVFs were supplied by the MMA, followed by the occipital artery (OCC) and ascending pharyngeal artery.

\section{Treatment Characteristics}

The interventions were successfully accomplished in all patients. A total of 50 treatment sessions were performed. In $86 \%$ of patients, only 1 session was needed for complete obliteration of the DAVF. One or 2 arterial feeders were embolized in $94 \%$ of the cases (Table 2).

Treatment was performed using only TAA in 42 (97.7\%) fistulas. In only 1 case, transvenous embolization was necessary in association with the TAA to complete treatment. A transvenous remodeling balloon was used in $44 \%$ of sessions. A transarterial DLB catheter for NALEA injection was used in $41(82 \%)$ procedures. Both balloons were used simultaneously in $21(42 \%)$ interventions.

The most frequently used access was the MMA followed by the OCC. The average volume of NALEA injected was almost the same in the MMA and OCC arteries. In 13 procedures, a simultaneous injection was performed through the MMA and OCC.

In $29(85 \%)$ sinus wall DAVFs, the sinus was preserved. In 3 cases, the sinus was occluded through transarterial NALEA injection as planned. In the other 2 DAVFs, the nonfunctioning sinus was nonintentionally occluded but without any clinical impact. In those cases, a TVB was not used.

\section{Angiographic Outcome}

Immediate, complete angiographic occlusion was achieved in 39 (90.7\%) DAVFs. Of the 41 controlled DAVFs, 40 (97.6\%) were completely occluded at 6 months. One patient died before the 6month follow-up. Another patient whose postprocedural angiography showed complete DAVF occlusion refused angiographic follow-up.

\section{Clinical Outcome}

Of the 41 patients enrolled, 39 (95.1\%) were treated without major neurologic events or death during follow-up. One patient with a transverse-sigmoid fistula presented with cerebellar ischemia during 


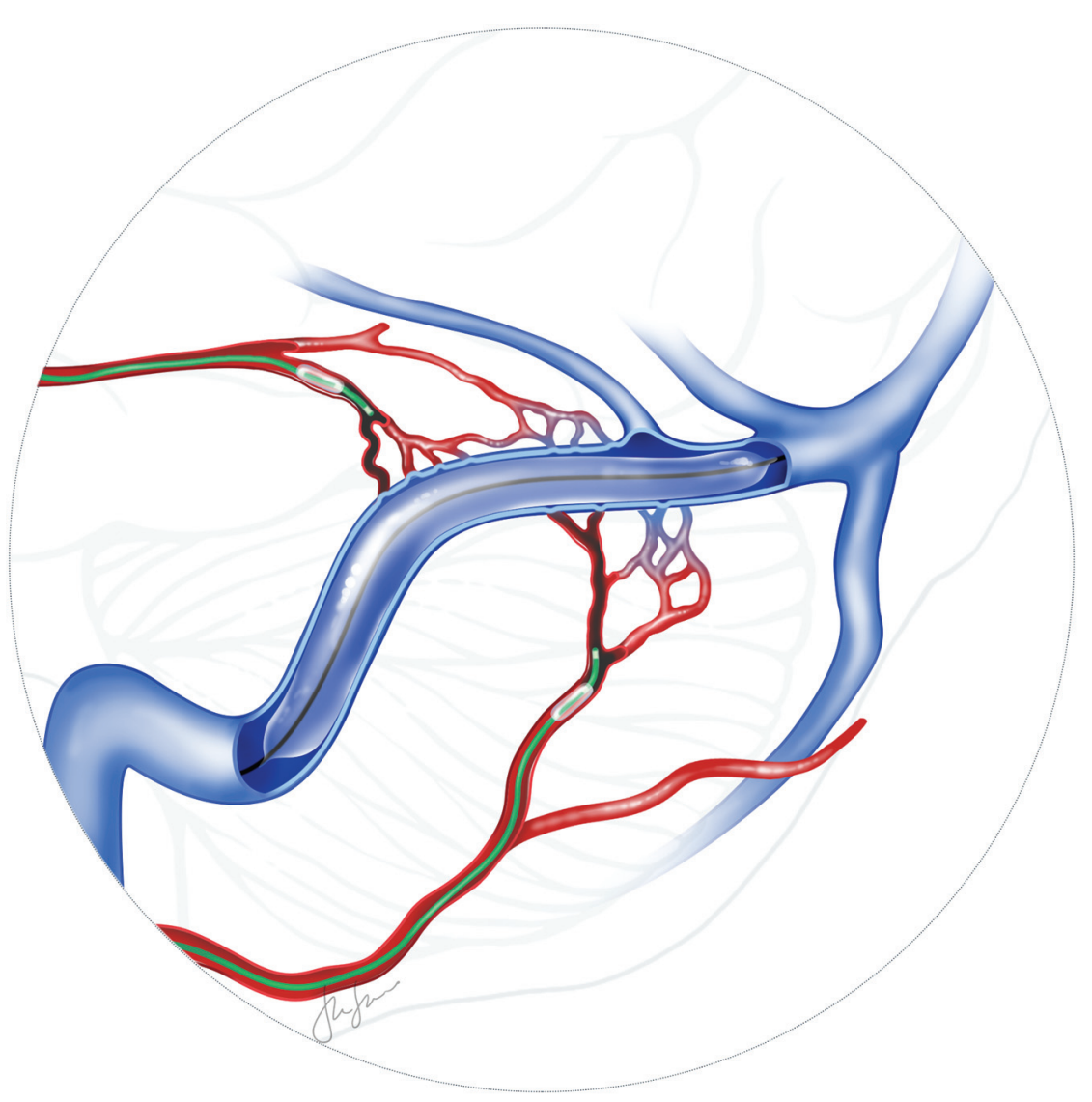

FIG 2. Schematic drawing demonstrates a DAVF of the transverse sinus. A DLB catheter is inside the petrosquamous branch of the MMA, and another DLB catheter is inside the mastoid branch of the OCC. A third balloon catheter is positioned inside the transverse sinus and inflated to protect the sinus lumen. Observe that the DLB catheters avoid liquid embolic agent reflux.

Endovascular treatment is wellestablished as the first-line treatment to manage DAVFs. ${ }^{2}$ The TAA for fistulas with DLVD has become the criterion standard since the introduction of NALEAs. It was first reported by Rezende et al, ${ }^{14}$ in 2006, when a patient with a lesser sphenoid wing region DAVF was treated by transarterial embolization with Onyx, achieving complete occlusion in a single session. Since then, the safety and effectiveness of NALEAs in the treatment of DAVFs have been consistently reported. ${ }^{2}$

However, the TAA has some limitations. Considering that the treatment goal for DAVFs with DLVD embolization is to achieve occlusion of the arteriovenous shunt, including the outflow portion of the draining vein, some technical challenges may be encountered to promote proper embolization across tiny arterial feeders up to the venous site of the fistula. Notably, it is difficult to manage the balance between anterograde flow and reflux to predict the progression of the embolic agent toward the fistula. ${ }^{2,15}$ A position close to the fistulous zone, which is the most often intended, is difficult to reach if arterial feeders are very tortuous or have a small caliber. Additionally, in some cases, major embolic agent reflux

treatment. Total recovery of ataxia was observed after 1 month. The only reported death occurred 3 months after treatment, due to an unrelated cause (complication of a pancreatectomy).

Complications of any kind occurred in 4 (9.7\%) patients, including 2 cases of facial palsy, 1 case of alopecia, and 1 case of scalp necrosis. Of the 2 cases of facial palsy, one patient completely recovered and the other patient partially improved. No catheter was retained by the embolic agent.

At the last follow-up, 32 (78\%) patients were asymptomatic, 7 (17\%) improved, and only 1 (2.4\%) deteriorated. One patient died.

\section{DISCUSSION}

The present study represents the largest series regarding endovascular treatment of DAVFs assisted by transarterial and/or transvenous balloons. Forty-one patients with 43 DAVFs were included. All patients except 1 were treated solely through a TAA. The treatment strategy was based on flow/pressure control. Injection through an inflated balloon catheter at the arterial feeder improves the penetration of embolic agent because it creates a barrier to reflux backflow, moving the gradient pressure toward the fistula. At the venous side, the mechanical presence of an inflated balloon builds a sinus lumen mold for the embolic agent, protecting it from inadvertent occlusion of the sinus or embolic agent migration. along the microcatheter may be observed, compelling the operator to stop the injection to prevent embolization into eloquent arteries or microcatheter retention inside the reflux. ${ }^{6,8-10}$

On the other hand, DAVFs located at the dural sinus wall are classically treated through a TVA, with sinus sacrifice whenever possible. ${ }^{1}$ Some authors advocate the use of the TAA to preserve the sinus lumen, but some controversy exists. Ertl et $\mathrm{al}^{1}$ showed that sinus-occluding treatment is related to a higher rate of definitive fistula occlusion but was accompanied by a significantly higher complication rate. In contrast, the sinus-preserving approach offered a lower rate of occlusion but a very low complication rate. Most complications are related to an inadvertent occlusion of a functioning sinus. The TAA poses a large challenge because it is essential to occlude all the fistulous connections at the dural sinus wall while avoiding penetration of the embolic agent inside the sinus. ${ }^{5}$

To improve the penetration of NALEAs toward the fistula during the TAA, some strategies have been used, including the pressure-cooker technique using glue or coils and the use of a balloon besides the microcatheter. ${ }^{9,16}$

The use of a DLB catheter for NALEA injection was described in 2013 and has been expanded since then. ${ }^{17}$ The device has 2 lumens: the first lumen is dedicated to the guidewire, and the second lumen is dedicated to balloon inflation. Once the wire is 
Table 1: Baseline characteristics of patients and DAVFs ${ }^{a}$

\begin{tabular}{|c|c|}
\hline Patient Demographi & \\
\hline Total No. of patients & 41 \\
\hline Mean age (yr) & $57.3 \pm 13.8$ \\
\hline Male/female ratio & $1.16: 1$ \\
\hline \multicolumn{2}{|l|}{ Clinical presentation } \\
\hline Asymptomatic & $4(9.8 \%)$ \\
\hline Symptomatic & $37(90.2 \%)$ \\
\hline Headache & $27(65.8 \%)$ \\
\hline Tinnitus & $21(51.2 \%)$ \\
\hline Intracranial hypertension & $10(24.4 \%)$ \\
\hline Hemorrhage & 7 (17.1\%) \\
\hline Seizure & $4(9.8 \%)$ \\
\hline Cognitive impairment & $3(7.3 \%)$ \\
\hline \multicolumn{2}{|l|}{ DAVF location ${ }^{\mathrm{b}}$} \\
\hline Transverse/sigmoid sinus & $21(48.8 \%)$ \\
\hline Transverse/torcula & $8(18.6 \%)$ \\
\hline Tentorial & $7(16.3 \%)$ \\
\hline Superior sagittal sinus & $5(11.6 \%)$ \\
\hline Lesser sphenoid wing & $1(2.3 \%)$ \\
\hline Convexity & $1(2.3 \%)$ \\
\hline \multicolumn{2}{|l|}{ DAVF classification (Cognard) } \\
\hline I & $4(9.3 \%)$ \\
\hline Ila & $8(18.6 \%)$ \\
\hline $\mathrm{Ilb}$ & $6(13.9 \%)$ \\
\hline $\mathrm{Ila}+\mathrm{b}$ & $16(37.2 \%)$ \\
\hline III & 7 (16.3\%) \\
\hline IV & $2(4.6 \%)$ \\
\hline$\vee$ & $0(0 \%)$ \\
\hline \multicolumn{2}{|l|}{ Arterial feeders } \\
\hline Middle meningeal & $40(93.0 \%)$ \\
\hline Occipital & $38(88.3 \%)$ \\
\hline Ascending pharyngeal & $10(23.2 \%)$ \\
\hline ICA (dural branches) & $7(16.2 \%)$ \\
\hline Vertebral & $5(11.6 \%)$ \\
\hline Superficial temporal & $4(9.3 \%)$ \\
\hline Posterior meningeal & $4(9.3 \%)$ \\
\hline Ophthalmic & $3(6.9 \%)$ \\
\hline Davidoff and Schechter & $3(6.9 \%)$ \\
\hline Posterior auricular & $1(2.3 \%)$ \\
\hline \multicolumn{2}{|c|}{ Venous sinus angiographic features ${ }^{c}$} \\
\hline Isolated sinus & $3(8.8 \%)$ \\
\hline Functional sinus & $13(38.2 \%)$ \\
\hline
\end{tabular}

removed, the NALEA can be injected through the lumen. When the balloon is inflated, it is able to simulate a "wedge and plug" effect, which is mandatory for NALEA anterograde migration. Therefore, it allows a more aggressive embolization, with a prolonged injection time of higher volumes of embolic material without reflux. One of the main disadvantages of this technique is that the navigability of the DLB catheter is poorer than that of other dimethyl-sulfoxide-compatible microcatheters. ${ }^{6,10,16}$

Deng et $\mathrm{al}^{9}$ reported a case series of 8 patients with DAVFs who underwent balloon-assisted transarterial embolization. However, instead of using a DLB catheter, a standard remodeling balloon was placed parallel to a microcatheter. Complete occlusion of the fistula was achieved in all patients without complications.

In 2013, Paramasivam et $\mathrm{al}^{11}$ reported their experience with DLBs in the treatment of 22 patients with different lesions, including intracranial and extracranial arteriovenous malformations,
Table 2: Treatment characteristics and results ${ }^{a}$

\begin{tabular}{|c|c|}
\hline No. of Treatment Pro & \\
\hline Total No. of sessions & 50 \\
\hline 1 session per DAVF & $37(86.1 \%)$ \\
\hline 2 sessions per DAVF & $5(11.6 \%)$ \\
\hline 3 sessions per DAVF & $1(2.3 \%)$ \\
\hline \multicolumn{2}{|c|}{ No. of arteries embolized per session } \\
\hline 1 & $22(44 \%)$ \\
\hline 2 & $25(50 \%)$ \\
\hline 3 & $3(6 \%)$ \\
\hline \multicolumn{2}{|l|}{ Embolized artery ${ }^{b}$} \\
\hline Middle meningeal & $42(51.9 \%)$ \\
\hline Occipital & $35(43.2 \%)$ \\
\hline Superficial temporal & $3(3.7 \%)$ \\
\hline Ascending pharyngeal & $1(1.2 \%)$ \\
\hline \multicolumn{2}{|c|}{ Volume of NALEA injected per pedicle $(\mathrm{mL})$} \\
\hline Middle meningeal & $4.48(0.8-13.4)$ \\
\hline Occipital & $4.53(0.7-15.6)$ \\
\hline \multicolumn{2}{|c|}{ Duration of NALEA injection per pedicle (min) } \\
\hline Middle meningeal & $33.4(8-110)$ \\
\hline Occipital & $27.3(8-62)$ \\
\hline \multicolumn{2}{|l|}{ Treatment approach per DAVF } \\
\hline Arterial & $42(97.7 \%)$ \\
\hline Arterial + venous & $1(2.3 \%)$ \\
\hline \multicolumn{2}{|l|}{ Balloon use per session } \\
\hline Only transarterial & $20(40 \%)$ \\
\hline Only transvenous & $1(2 \%)$ \\
\hline Transarterial + transvenous & $21(42 \%)$ \\
\hline None & $8(16 \%)$ \\
\hline \multicolumn{2}{|l|}{ Angiographic outcome } \\
\hline Immediate total occlusion & $39 / 43(90.7 \%)$ \\
\hline 6-Month total occlusion & $40 / 41(97.6 \%)$ \\
\hline \multicolumn{2}{|l|}{ Clinical outcome } \\
\hline Asymptomatic & $32(78.1 \%)$ \\
\hline Improvement of symptoms & 7 (17.1\%) \\
\hline Worsening of symptoms & $1(2.4 \%)$ \\
\hline Death & $1(2.4 \%)$ \\
\hline \multicolumn{2}{|l|}{ Complications } \\
\hline Facial palsy & 2 \\
\hline Cerebellar ischemia & 1 \\
\hline Alopecia & 1 \\
\hline Scalp necrosis & 1 \\
\hline
\end{tabular}

${ }^{a}$ Values are presented as number (\%) unless stated otherwise.

${ }^{\mathrm{b}}$ Based on the total number of embolized arteries $(n=81)$.

vein of Galen malformations, and dural fistulas. Among 7 patients with DAVFs, 4 optimal occlusions, 2 suboptimal occlusions, and 1 failed catheterization resulted. In 2 cases, reflux across the balloon was observed, and 1 MMA rupture with extradural hemorrhage occurred.

A nonrandomized study, including only isolated-type DAVFs, compared the results of Onyx embolization using a DLB catheter with those using a nonballoon microcatheter. ${ }^{10}$ The balloon group showed complete occlusion of the DAVF in 13 patients and nearcomplete occlusion in 2 patients, while the nonballoon group showed complete occlusion in 5 patients, near-complete occlusion in 5 patients, and incomplete occlusion in 4 patients. The balloon group presented with a lower mean procedural time, a lower Onyx injection time, and fewer embolized feeders than the nonballoon group. Complication rates were equal in both groups.

The present series achieved $91 \%$ and $98 \%$ total occlusion rates in immediate and late angiographic follow-up, respectively. Only 1 embolization session was necessary in $86 \%$ of the fistulas. Nine 
DAVFs with DLVD were treated, with total occlusion in all cases. Considering only sinus wall fistulas, angiographic occlusion was reached in $88 \%$ immediately and $97 \%$ at the 6-month control.

Two complications, namely alopecia and skin necrosis, resulted from the radiation dose and inadvertent occlusion of the branches supplying the scalp. Facial palsies were related to NALEA penetration in the petrous branch of the MMA during the treatment of DAVFs involving the torcula. In both cases, the balloon was placed inside the OCC while the MMA was embolized using a standard microcatheter. No case of inadvertent reflux in the feeder when the DLB catheter was used occurred. One death was observed in followup and was not related to the treatment. Most patients improved.

The use of transosseous branches of the OCC has been reported as poorly suitable for Onyx injection because possible major resistance through these branches limits the embolic agent penetration toward the fistulous point. ${ }^{6,13}$ It seems that the use of the balloons changes this paradigm. Although the MMA remained the feeder of choice in the present series, 35 occipital arteries were embolized, 33 of them with a DLB catheter.

Although the use of transarterial DLB catheters has overcome the reflux issue, unintentional NALEA penetration into the sinus must be managed and avoided. The transvenous balloon can minimize leakage of NALEA into the venous sinus. ${ }^{12,13,18}$ Based on its pathologic origin, multiple abnormal arteriovenous connections are present in the dural sinus wall, not inside the sinus itself. Therefore, occlusion of the connections in the sinus wall seems to be more reasonable than occlusion of the entire lumen, especially when the sinus is used for normal cerebral drainage. 5,10

In some cases of dural sinus wall fistulas, the use of TVB is impossible or unnecessary, including isolated sinus, venous sinus thrombosis causing partial occlusion, severe stenosis $(>80 \%)$, and a very large sinus. The dedicated balloon has a maximum diameter of $10 \mathrm{~mm}$. Although it is possible to use multiple balloons, we decided to not use this technique.

Vollherbst et $\mathrm{al}^{13}$ reported a retrospective series of 22 patients with DAVFs treated by a TAA assisted by a TVB; most DAVFs were located at the transverse and/or sigmoid sinus. The affected sinus could be preserved in all patients except 1 . The overall complete occlusion rate was $86.4 \%$. In our series, we used both transarterial and transvenous balloons simultaneously to treat 21 DAVFs, with late complete occlusion in all cases. No sinus was inadvertently occluded when the TVB was used. No ischemic or hemorrhagic lesions were observed secondary to transitory balloon occlusion of the sinus.

A major controversy is whether there is a reason for preserving a dural sinus that is nonfunctional. In our series, 6 of 18 nonfunctioning sinuses that were preserved were found to be functioning at the 6-month control angiography. The sinus may be nonfunctioning because of a hemodynamic competition, instead of an anatomic disruption, a true occlusion. Therefore, we believe that the re-establishment of the circulation inside a previously nonfunctioning sinus should be a treatment goal.

In the present series, double arterial simultaneous injection through the MMA and OCC was performed in 13 cases. The reasoning behind this technique is based on a balancing of the pressures. ${ }^{19}$ When the balloon is inflated in the OCC or in both the OCC and the MMA, it immediately decreases the pressure inside the sinus; therefore, the resistance to NALEA flow becomes lower. The balloon inside the sinus can be inflated or deflated according to the dynamics of the injection.

The use of balloons in endovascular treatment of DAVFs is a very promising strategy because it plays an important role in the hemodynamic balance across the fistula, optimizing the embolic agent flow toward the shunting point. Caution must be used regarding the volume of inflation in both balloons. ${ }^{12,13}$

\section{CONCLUSIONS}

Transarterial balloon-assisted treatment of dural arteriovenous fistulas with or without transvenous balloon protection was shown to be safe and very effective. Long-term follow-up and comparative studies are required to provide stronger conclusions regarding the superiority of this technique.

\section{ACKNOWLEDGMENTS}

We gratefully acknowledge Lara Laghetto from Visualmedics for preparing the illustration.

\section{REFERENCES}

1. Ertl L, Brückmann H, Kunz M, et al. Endovascular therapy of lowand intermediate-grade intracranial lateral dural arteriovenous fistulas: a detailed analysis of primary success rates, complication rates, and long-term follow-up of different technical approaches. $J$ Neurosurg 2017;126:360-67 CrossRef Medline

2. Abud TG, Nguyen A, Saint-Maurice JP, et al. The use of Onyx in different types of intracranial dural arteriovenous fistula. AJNR Am J Neuroradiol 2011;32:2185-91 CrossRef Medline

3. Lv X, Jiang C, Li Y, et al. The limitations and risks of transarterial Onyx injections in the treatment of grade I and II DAVFs. Eur J Radiol 2011;80:e385-88 CrossRef Medline

4. Cognard C, Gobin YP, Pierot L, et al. Cerebral dural arteriovenous fistulas: clinical and angiographic correlation with a revised classification of venous drainage. Radiology 1995;194:671-80 CrossRef Medline

5. Jittapiromsak P, Ikka L, Benachour N, et al. Transvenous balloonassisted transarterial Onyx embolization of transverse-sigmoid dural arteriovenous malformation. Neuroradiology 2013;55:345-50 CrossRef Medline

6. Clarençon F, Di Maria F, Gabrieli J, et al. Double-lumen balloon for Onyx embolization via extracranial arteries in transverse sigmoid dural arteriovenous fistulas: initial experience. Acta Neurochir (Wien) 2016;158:1917-23 CrossRef Medline

7. Chiu AHY, Grace A, Wenderoth JD. Double-lumen arterial balloon technique for Onyx embolization of dural arteriovenous fistulas: initial experience. J Neurointerv Surg 2014;6:400-03 CrossRef Medline

8. Dabus G, Linfante I, Galdámez MM. Endovascular treatment of dural arteriovenous fistulas using dual lumen balloon microcatheter: technical aspects and results. Clin Neurol Neurosurg 2014;117:22-27 CrossRef Medline

9. Deng JP, Zhang T, Li J, et al. Treatment of dural arteriovenous fistula by balloon-assisted transarterial embolization with Onyx. Clin Neurol Neurosurg 2013;115:1992-97 CrossRef Medline

10. Kim JW, Kim BM, Park KY, et al. Onyx embolization for isolated type dural arteriovenous fistula using a dual-lumen balloon catheter. Neurosurgery 2016;78:627-36 CrossRef Medline

11. Paramasivam S, Nimi Y, Fifi J, et al. Onyx embolization using duallumen balloon catheter: initial experience and technical note. $J$ Neuroradiol 2013;40:292-302 CrossRef Medline

12. Piechowiak E, Zibold F, Dobrocky T, et al. Endovascular treatment of dural arteriovenous fistulas of the transverse and sigmoid 
sinuses using transarterial balloon-assited embolization combined with transvenous balloon protection of the venous sinus. AJNR Am J Neuroradiol 2017;38:1984-89 CrossRef Medline

13. Vollherbst DF, Ulfert C, Neuberger U, et al. Endovascular treatment of dural arteriovenous fistulas using transarterial liquid embolization in combination with transvenous balloon-assisted protection of the venous sinus. AJNR Am J Neuroradiol 2018;39:1296-302 CrossRef Medline

14. Rezende MT, Piotin M, Mounayer C, et al. Dural arteriovenous fistula of the lesser sphenoid wing region treated with Onyx: technical note. Neuroradiology 2006;48:130-34 CrossRef Medline

15. Cognard C, Januel AC, Silva NA Jr, et al. Endovascular treatment of intracranial dural arteriovenous fistulas with cortical venous drainage: new management using Onyx. AJNR Am J Neuroradiol 2008;29:23541 CrossRef Medline
16. Chapot R, Stracke P, Velasco A, et al. The pressure cooker technique for the treatment of brain AVMs. J Neuroradiol 2014;41:87-91 CrossRef Medline

17. Kim ST, Jeong HW, Seo J. Onyx embolization of dural arteriovenous fistula, using Scepter $\mathrm{C}$ balloon catheter: a case report. Neurointervention 2013;8:110-14 CrossRef Medline

18. Guo F, Zhang Y, Liang S, et al. The procedure-related complications of transarterial Onyx embolization of dural arteriovenous fistula using transvenous balloon protection. World Neurosurg 2018;116: e203-10 CrossRef Medline

19. Abud DG, Riva R, Nakiri GS, et al. Treatment of brain arteriovenous malformations by double arterial catheterization with simultaneous injection of Onyx: retrospective series of 17 patients. AJNR Am J Neuroradiol 2011;32:152-58 CrossRef Medline 